\title{
educação

\section{A inserção profissional de um egresso do PIBID: O caso de uma professora de matemática}

\author{
Fernanda Lahtermaher Oliveira ${ }^{\mathrm{I}}$ \& Giseli Barreto \\ DA CRUZ
}

\section{Universidade Federal do Rio de Janeiro, Brasil}

\begin{abstract}
O artigo focaliza a inserção profissional de uma professora de matemática que passou pelo PIBID e hoje atua no Ensino Fundamental II de uma escola pública municipal do Rio de Janeiro, Brasil. Foi realizado um estudo de caso etnográfico, de modo a que as experiências, a formação e as expectativas da professora fossem compreendidas por meio de entrevistas em profundidade e observação participante. Teoricamente, o artigo dialoga com Cochran-Smith, Fiorentini e Marcelo Garcia. Os resultados demonstram que: há uma tendência ao isolamento por parte da professora iniciante; existe uma força da área e uma crença epistemológica no ensino transmissivo; o PIBID aparece como uma contribuição no que se refere ao conhecimento do contexto profissional.
\end{abstract}

Palavras-chave: Inserção profissional docente; Professora de matemática; Estudo de caso etnográfico

\section{N T ROD U Ç Ã O}

Este artigo apresenta um estudo de caso etnográfico acerca dos aspectos facilitadores e dificultadores da inserção profissional docente, no contexto de uma escola do sistema público de ensino brasileiro, por parte de uma professora de matemática egressa do Programa Institucional de Bolsa de Iniciação à Docência (PIBID) da Universidade Federal do Rio de Janeiro (UFRJ).

O interesse em torno do tema da inserção profissional docente se justifica em face da complexidade que cerca esse momento da vida profissional. Trata-se do período em que o professor adentra o campo de atuação, não mais como estudante, mas como licenciado, na condição de responsável efetivo pelo desenvolvimento das aprendizagens de seus alunos. Conforme evidencia a literatura da área, nos cenários brasileiros e internacional (André, 2018; Cochran-Smith, 2012; Marcelo, 2009, 2010, 2011; Marcelo \& Vaillant, 2017; Nóvoa, 2009), essa fase é marcada por tensões e constrangimentos, mas também por aprendizagens intensivas, em que os professores iniciantes questionam a sua formação, bem como a sua prática.

A aprendizagem da docência ocorre ao longo de toda a vida e muitos autores têm dedicado atenção ao desenvolvimento profissional de professores, como é o caso de Cochran- 
Smith (2012), Marcelo (2009), Tardif (2002) e Huberman (2000). A etapa referente à inserção profissional tem chamado especial atenção dos pesquisadores nacionais e internacionais, pois há uma preocupação com esse momento, entendido como um dos mais importantes do ciclo de vida profissional. Conforme assinala Marcelo (1999), "falar da carreira docente não é mais do que reconhecer que os professores, do ponto de vista do 'aprender a ensinar, passam por diferentes etapas, as quais representam exigências pessoais, profissionais, organizacionais, contextuais, psicológicas, etc., específicas e diferenciadas" (p. 112).

Nesse entendimento, Veenman (1984) assinala que o primeiro ano de exercício profissional é de intensa aprendizagem, posto que o professor precisa ensinar e aprender a ensinar ao mesmo tempo, havendo várias tentativas e erros, que o tornam um período de sobrevivência, em que há uma valorização de ações práticas. $O$ autor desenvolve o conceito de "choque de realidade", ao se referir à situação dos iniciantes quando se deparam com o contexto escolar, já que o cotidiano tem apresentado grande abandono de professores na fase inicial devido a diferentes fatores, como condições salariais, desvalorização, indisciplina dos alunos, pouca participação nas decisões da escola. Além disso, se sentem isolados, recebem as turmas com maior dificuldade e não têm apoio da instituição.

Tardif (2002) reconhece que a inserção “é um período realmente importante na história profissional do professor, determinando inclusive seu futuro e sua relação com o trabalho" (p. 11). As primeiras experiências vivenciadas pelos professores em início de carreira têm influência direta sobre a sua decisão de continuar ou não na profissão, porque é um período marcado por sentimentos contraditórios que desafiam cotidianamente o professor e sua prática docente.

Huberman (2000) ressalta que além do choque de realidade outros desafios fazem parte desta etapa, como a sobrevivência e a descoberta. É a descoberta que ameniza as dificuldades, sendo que "o entusiasmo inicial, a exaltação por estar, finalmente, em situação de responsabilidade (ter a sua sala de aula, os seus alunos, o seu programa), por se sentir num determinado corpo profissional" (p. 39) são elementos que servem de motivação e fazem com que os professores iniciantes sobrevivam a esse momento. É essa descoberta da profissão que contribui para a permanência na docência.

É no entendimento de que esse momento faz parte de uma etapa-chave do desenvolvimento profissional que consideramos necessário investigar os professores iniciantes no seu contexto profissional. Escolhemos analisar o caso de inserção de uma professora de matemática por entendermos ser uma dasáreas desafiantes para a formação e a atratividade de novos professores. No contexto brasileiro, a literatura da área (Fiorentini \& Oliveira, 2013; Gatti, 2010) tem evidenciado problemas que se relacionam com a formação dos professores que ensinam matemática e a sua permanência na profissão, como a atratividade da carreira docente, a valorização profissional, o lugar curricular da didática nos cursos, o modelo de estágio, as políticas e programas de inserção e indução profissional. Resultados de pesquisas revelam escassez de referenciais práticos na formação inicial de seu professor, notadamente marcada pelo distanciamento entre as práticas formativas da universidade e o local de atuação, as escolas, como argumentam Fiorentini e Oliveira (2013), Gatti (2008, 2010), Ferreira e Moreira (2013). Além disso, resultados de avaliação externa apontam baixos índices de aproveitamento dos estudantes em matemática, desafiando 
ainda mais o ensino dos conteúdos dessa disciplina.

Escolhemos intencionalmente uma professora iniciante na área de matemática que teve a chance de participar do PIBID - Programa Institucional de Bolsas de Iniciação à Docência, por entendermos que esse programa, estritamente voltado para a formação inicial, da prática profissional, pela via da parceria universidade-escola, tende a favorecer a superação dos problemas anteriormente sinalizados, constituindose, portanto, como uma fonte relevante de mobilização de saberes para um professor em situação de inserção profissional.

O PIBID foi criado pelo Ministério da Educação do governo central brasileiro (MEC) em parceria com a Coordenação de Aperfeiçoamento Pessoal de Nível Superior (CAPES) no ano de 2007. Além de incentivar a formação docente em nível superior para a educação básica e contribuir para a valorização do magistério, o programa tem como objetivo inserir os licenciandos no cotidiano das escolas das redes públicas de ensino, propiciando oportunidades de aprendizagem da docência através da criação e desenvolvimento de projetos de ensino.

O PIBID vem demonstrando ser um diferencial na formação de professores, contribuindo com experiências em situações de ensino que possibilitam uma vivência em sala de aula, uma reflexão sobre o processo de ensino-aprendizagem e a investigação da própria prática, como evidenciam Cruz (2019a) e Campelo e Cruz (2017). Por esse motivo, olhar para os egressos desse programa se torna relevante para compreender a contribuição que o PIBID pode trazer na inserção profissional de professores.

Assim, procuramos neste trabalho debruçar-nos sobre a relação entre o PIBID e a inserção profissional docente de uma professora que ensina matemática, através de um estudo de caso etnográfico, conduzido pelo objetivo de investigar os aspectos facilitadores e dificultadores da inserção profissional, por meio da análise de experiências vivenciadas e dos saberes docentes mobilizados com mais recorrência pela docente durante o seu processo de inserção profissional. Desse modo, inscrevese como questão problematizadora do estudo a seguinte indagação: como ocorre a inserção profissional de uma professora de matemática que passou pelo PIBID, um programa nacional brasileiro delineado especialmente para favorecer a iniciação à docência? Apostamos na hipótese de que professores em processo de inserção profissional docente, egressos desse programa, vivenciam essa fase da carreira, amplamente conhecida pelo "choque de realidade" (Veenman, 1984), de modo menos traumático. Supomos que eles se sintam mais preparados para enfrentar os desafios do início da docência, sabendo aonde buscar recursos para enfrentar dificuldades próprias desse período. Nessa direção, delineiase o estudo de caso de uma professora de matemática egressa do PIBID em situação de inserção profissional.

\section{PERCURSO METOdOLÓgico}

A escolha da professora de matemática cuja docência constitui o caso estudado está relacionada com duas outras investigações, em que atuamos como pesquisadores de campo. A primeira foi a pesquisa que desenvolvemos no âmbito do GEPED ${ }^{1}$, sob a coordenação de Cruz (2015-2018), que analisou concepções e práticas didáticas de egressos de cursos de

${ }^{1}$ GEPED - Grupo de Estudos e Pesquisas em Didática e Formação de Professores, da Faculdade de Educação da UFRJ. 
licenciatura da UFRJ. Foram 16 os professores em situação de inserção que participaram desse estudo, sendo um deles a de matemática, sujeito do estudo de caso em tela. E a segunda foi a pesquisa interinstitucional coordenada por André (2015-2017), que investigou professores iniciantes egressos de três diferentes programas de iniciação à docência, a saber: PIBID, Residência Pedagógica e Bolsa Alfabetização ${ }^{2}$, sendo a professora de matemática uma das participantes pela via do PIBID. Em ambas as pesquisas, o estudo de caso em questão se inseriu na segunda etapa do trabalho metodológico, para fins de aprofundamento analítico, constituindo-se, assim, em um contexto de pesquisa interinstitucional. Parte dos achados das duas pesquisas poderão ser conferidos nas publicações de Cruz (2019b), em relação à primeira, e de André (2018), em relação à segunda.

No que se refere à pesquisa realizada pelo GEPED, a escolha dos sujeitos se deu pela indicação de professores de Didática e Prática de Ensino da instituição de ensino superior participante, a UFRJ, que atuaram como informantes privilegiados do estudo. A primeira etapa dessa pesquisa consistiu na realização de entrevistas com os professores iniciantes, ficando a segunda etapa destinada aos estudos de casos.

Quanto à pesquisa coordenada por André (2018), os sujeitos foram contatados por diferentes instituições de ensino superior envolvidas com os programas de iniciação à docência selecionados, no sentido de responderam uma survey, aplicada com o propósito de conhecer quem são os egressos desses programas e as condições em que se inserem profissionalmente na docência. A aplicação da survey consistiu na primeira etapa da pesquisa, envolvendo egressos de 18 instituições de ensino superior de nove estados do Brasil, em um total de 1.237 participantes. A escolha desses estados decorreu da possibilidade de acesso aos dados por parte dos integrantes da equipe de pesquisa. Para o levantamento de dados, que teve início em 2015, foram considerados os egressos que concluíram os programas de iniciação à docência nos anos de 2011 a 2014. A segunda etapa dessa pesquisa também foi destinada aos estudos de caso.

Os critérios definidos para que o professor participasse do estudo de caso, no que toca à primeira pesquisa, foram: aceitação (autorização), viabilidade institucional (permissão), localização da escola (mobilidade dos pesquisadores), tempo (exequibilidade da pesquisa) e alcance de diferentes etapas de ensino da educação básica (Ensino Fundamental I e II e Ensino Médio), bem como de diferentes redes públicas (municipal e estadual). No tocante à segunda pesquisa, além da concordância, era preciso que o professor respondesse por completo à survey, que se encontrasse em sua primeira experiência profissional, não tivesse outra licenciatura, concluísse o curso e ingressasse na rede de ensino entre 2011 e 2016.

Nesse percurso, chegamos até à professora de matemática, concluinte do curso de licenciatura na UFRJ, no ano de 2013, e ingressante na rede municipal de educação do Rio de Janeiro-RJ/BR, no ano de 2015, tendo sido bolsista do PIBID durante todo o ano de 2012. A escola em que atua não apresenta outros professores de matemática em processo de inserção profissional, embora existam

${ }^{2}$ Programa Institucional de Bolsa de Iniciação à Docência (PIBID), em âmbito federal; Residência Pedagógica da Universidade Federal de São Paulo-SP/BR (UNIFESP); e Bolsa Alfabetização, do governo do estado de São Paulo-SP/RJ. Os três programas concediam bolsas a estudantes de licenciatura para desenvolver atividades em escolas da educação básica, sob a supervisão dos professores dos cursos de licenciatura e professores das escolas parceiras, conforme justifica André (2018). 
professores que estejam iniciando na rede municipal. Dessa maneira, o estudo de caso delimitou-se intencionalmente na inserção profissional desta professora na instituição de ensino em que se encontrava em atuação.

Para desenvolver o estudo de caso, optamos pela realização do tipo etnográfico, com base nas orientações de Becker (1997), Fonseca (1999) e Weber (2007). Assumimos o estudo de caso como um método em que se pode adquirir conhecimento a partir da exploração intensa de um contexto específico (Becker, 1997), e a etnografia enquanto abordagem teóricometodológica capaz de auxiliar a compreensão desse fenômeno educativo particular.

A escolha pelo estudo de caso etnográfico se justifica em face da necessidade de relativizar o olhar com base na análise das diferentes culturas e, no âmbito desta pesquisa, por se tratar de imersão prolongada em uma escola pública municipal, exigindo-nos continuamente o exercício de estranhar o que nos parecia familiar.

O universo escolar é repleto de discursos, representações, identidades, memórias e trajetórias que compõem um espaço de socialização. Por essa razão, a descrição densa da cultura, proposta por Geertz (1989), auxilia na compreensão dessa realidade, de modo que o estudo de caso se justifica devido à complexidade e particularidade do processo de inserção profissional da professora investigada.

A realização do estudo seguiu o modelo proposto por Weber (2007) evidenciando as diferentes fases da pesquisa de proximidade. Inicialmente, houve um distanciamento por nossa parte para a escolha do contexto e do foco partindo de leituras intensivas sobre a literatura da área e documentos, sendo possível levantar as primeiras hipóteses e realizar os contatos iniciais com a professora. No segundo momento, denominado de cotidiano, com duração entre outubro e dezembro de 2016, entramos em campo para observação das primeiras hipóteses, fazendo o registro de tudo o que estava sendo observado no diário de campo; nessa fase acompanhávamos a professora fazendo observações, registros, e promovendo conversas espontâneas sobre o que acontecia na sua sala de aula. A terceira fase foi de reorientação, durando um mês e meio (dezembro/2016 a janeiro/2017), onde foi preciso um novo distanciamento, em parte para análise dos objetivos e atenção às hipóteses, mas também decorrente das férias escolares. Entre fevereiro e junho de 2017 ocorreu a fase de verificação, comportando nova entrada na escola para realização da observação participante e de entrevistas em profundidade com a professora e a diretora da escola ${ }^{3}$. Para as entrevistas elaborámos um roteiro semiestruturado tendo como base nossas reflexões iniciais. O momento final foi de desinvestimento e ruptura com o campo.

Durante a primeira etapa de imersão em campo (outubro a dezembro de 2016) foram observadas as aulas da professora em diversas turmas do $6 .^{\circ}$ ao $9 .^{\circ}$ ano do Ensino Fundamental. Na etapa seguinte, de verificação (fevereiro a junho de 2017), houve uma mudança na grade horária da escola. Dessa maneira, as aulas observadas desenvolveramse nas seguintes turmas: em $2016-1802\left(8 .^{\circ}\right.$ ano), 1707 ( $7 .^{\circ}$ ano), 1605 (6. ano) e 1604 (6. ${ }^{\circ}$ ano); em 2017 - 1904 (9. ${ }^{\circ}$ ano), 1802 (8. ${ }^{\circ}$ ano) e 1604 ( $6 .^{\circ}$ ano).

A análise de dados foi feita a partir de três eixos iniciais que, no decorrer do seu exame, se transformaram em dois: a inserção profissional e os saberes docentes mobilizados com mais recorrência. Esses eixos foram elaborados segundo o objetivo da pesquisa, dirigido para

${ }^{3}$ Todos os participantes assinaram o Registro de Consentimento Livre e Esclarecido para a pesquisa. 
analisar aspectos facilitadores e dificultadores da inserção, bem como os saberes docentes mobilizados com mais recorrência, tendo sempre em mente a experiência no PIBID. A partir dos eixos definidos a priori, foram criadas categorias de análise. As categorias foram produzidas pelo e no processo analítico e modificadas pelo campo. É por isso que na etnografia o pesquisador deve estar atento às suas hipóteses, mas sabendo que poderão ser modificadas ao longo do trabalho. Nesse caso, a entrada em campo foi fundamental para perceber o que aparece como evitação e pertencimento da professora investigada, afetando as categorias propostas. No quadro a seguir, é possível identificar como os dados foram organizados no primeiro momento do trabalho.

O quadro evidencia os eixos e as categorias desenvolvidos no campo para análise do que estava sendo observado e a recorrência com que apareceram ao longo da pesquisa. As categorias são o que aparece de forma mais intensiva e estão identificadas em situações, acontecimentos, interações, transcrições e recortes do diário de campo e das entrevistas, demonstrando o ponto de vista da professora de forma densa. Embora determinadas categorias tenham tido um padrão de recorrência maior que outras, isso não invalidou a sua importância em função da inter-relação existente entre elas e a temática central.

O quadro revela como o eixo sobre o PIBID apresenta menos categorias, e por isso optou-se por integrá-lo nos outros eixos. As categorias são reagrupadas de acordo com as semelhanças que apresentam, o número de vezes em que aparecem e a literatura disponível na área.

QUADRO 1

Eixos e categorias de análise

\begin{tabular}{|l|l|l|}
\hline $\begin{array}{c}\text { Aspectos facilitadores e } \\
\text { dificultadores da in serção } \\
\text { profissional }\end{array}$ & $\begin{array}{c}\text { Saber es docentes mobilizados } \\
\text { com mais recorrência }\end{array}$ & $\begin{array}{c}\text { Experiências vivenciadas no } \\
\text { PIBID que auxiliam a } \\
\text { inserção }\end{array}$ \\
\hline Relação com os professores & Ensino transmissivo & $\begin{array}{l}\text { Familiaridade com o contexto } \\
\text { escolar }\end{array}$ \\
\hline Cultura da escola & Força da área matemática & $\begin{array}{l}\text { Propostas de atividades } \\
\text { diferenciadas }\end{array}$ \\
\hline Relação com os alunos & $\begin{array}{l}\text { A própria escolarização como } \\
\text { referência }\end{array}$ & $\begin{array}{l}\text { O contexto do PIBID } \\
\text { matemática }\end{array}$ \\
\hline Escolha pela carreira docente & Motivações de cunho familiar & \\
\hline Complexidade da área & $\begin{array}{l}\text { Influência da graduação e do } \\
\text { PIBID }\end{array}$ & \\
\hline
\end{tabular}

Fonte: própria, 2017.

QUADRO 2

Eixos e categorias de análise II

\begin{tabular}{|l|l|}
\hline \multicolumn{1}{|c|}{$\begin{array}{c}\text { Aspectos facilitadores e dificultadores da } \\
\text { inserção profissional }\end{array}$} & \multicolumn{1}{c|}{$\begin{array}{c}\text { Saberes docentes mob ilizados com mais } \\
\text { recorrência }\end{array}$} \\
\hline Relação com os professores & Ensino transmissivo \\
\hline Cultura da escola & Força da área matemática \\
\hline Relação com os alunos & Fontes dos sabres docentes \\
\hline $\begin{array}{l}\text { Escolha pela carreira docente } \\
\text { Complexidade da área }\end{array}$ & \\
\hline
\end{tabular}

Fonte: própria, 2017. 
Para sustentar a hipótese de cada categoria, selecionamos trechos dos diários de campo e entrevistas dando significado ao que estava sendo observado e, desta maneira, o quadro seguinte demonstra a reorganização dos eixos e categorias de forma sintetizada.

Desse modo, este estudo de caso descreve um fenômeno em particular, a inserção profissional de uma professora de matemática egressa do PIBID, resultado de um trabalho intensivo em campo e que permite reconhecer os caminhos percorridos para sua realização e as análises validadas pelo plano local.

\section{AsPECTOS CONTEXTUAIS E T E Ó R I C O S}

Para compreender como ocorre a inserção profissional de uma professora de matemática operamos teoricamente com as ideias, concepções e conceitos de Fiorentini, Passos, e Lima (2016), Tardif (2002), Cochran-Smith e Lytle (1999) e Shulman (1986). Entendemos que os autores ajudam a situar a discussão sobre os saberes docentes no início da carreira e os dilemas e saberes do professor que ensina matemática.

No contexto brasileiro, os cursos de licenciatura em matemática são pouco procurados e com grande abandono. Além disso, a própria estrutura curricular apresenta uma série de questões que merecem ser problematizadas a fim de compreender as concepções e práticas dos professores no que se refere ao currículo, à formação didática e à parceria que se estabelece entre a universidade e a escola básica.

Como evidencia Shulman (1986), há uma diferença entre o saber matemático que $o$ licenciando deve dominar e o conhecimento de um bacharel, pois o primeiro deve conhecer em profundidade a matemática enquanto prática social e não apenas o campo científico, mas sobretudo a matemática escolar. Com isso precisa saber justificar as estratégias utilizadas em aula, conhecendo outros conceitos e ideias, aproximando a matemática da sua relação com o mundo, enquanto instrumento de leitura e compreensão da realidade.

No entanto, o que se percebe por meio de pesquisas desenvolvidas no campo da educação matemática, como as de Fiorentini et al. (2016), é que se avançou pouco nos cursos de licenciatura em matemática, mesmo com as mudanças curriculares, e a introdução de novas disciplinas, visando uma matemática como organismo vivo e problematizado. Embora essa seja a preparação desejada, o que tem prevalecido é uma concepção de formação de professores em que a matemática ocupa um lugar central e o seu conteúdo é ensinado em uma perspectiva clássica e, às vezes, formalista estrutural, no lugar de um saber problematizado. Isso ocorre porque prevalece um entendimento de que "saber mais" $e$ "ensinar melhor" passa por domínio exclusivo do conhecimento a ser ensinado.

As autoras americanas Cochran-Smith e Lytle (1999) distinguem diferentes concepções de aprendizado da docência proporcionando distintas compreensões sobre como melhorar a formação de professores.

Com relação às concepções de formação de professores, as autoras apontam três compreensões diferentes, mas relacionadas: "conhecimento para a prática"; "conhecimento na prática"; "conhecimento da prática”. O primeiro tem como principal elemento o conhecimento formal que indica a compreensão de mais conteúdo, mais teorias educativas, mais estratégias de ensino como fundamentais para uma prática mais efetiva. Para as autoras, os professores precisam de levar para a prática o que aprendem fora da sala de aula (CochranSmith e Lytle, 1999).

O conhecimento na prática ou em prática 
desenvolve-se na perspectiva do conhecimento em ação, o que os professores sabem quando desenvolvem suas tarefas cotidianas, nas reflexões do professor sobre a ação, nas investigações e nas narrativas. Trata-se de um saber, de certa forma incerto ou espontâneo, desenvolvido a partir das situações vividas na sala de aula e na própria escola por professores que refletem sobre a sua prática e/ou que interagem com professores considerados "especialistas" no ensino, que sabem as razões pelas quais ensinam de tal forma e não de outra.

$\mathrm{Na}$ compreensão do conhecimento da prática, as discussões provenientes de como é produzido o conhecimento, quem o produz, para quem, o que conta como conhecimento são tão importantes quanto o uso que se faz dele e advêm da prática, sendo, deste modo, inseparáveis dos sujeitos que as compõem. Embora essas concepções sejam aparentemente conflitantes, elas coexistem, às vezes de maneira sutil, no campo da pesquisa e da prática educacional; portanto, não são excludentes. Suas fronteiras nem sempre estão visíveis; no entanto, é possível verificar as diferenças existentes entre elas no que se refere às imagens de conhecimento, prática e trabalho docente.

Na perspectiva de Tardif (2002), os saberes docentes são constituídos por meio de uma pluralidade e heterogeneidade de saberes, de modo que o saber da experiência ganha importância na medida em que a ação vivenciada coloca em evidência o saberfazer dos professores. Tipologicamente, o autor define os saberes docentes em quatro classificações, são elas: os saberes da formação profissional (das ciências da educação e da ideologia pedagógica); os saberes disciplinares; os saberes curriculares; os saberes experienciais.

A análise da inserção profissional pela via dos saberes docentes parte da compreensão de que existe um conhecimento profissional próprio do professor no exercício da sua profissão, saber esse que, como aponta Tardif (2002), é um saber amalgamado. A nossa pesquisa analisou a mobilização de saberes com a intenção de investigar as condições, limites e possibilidades da professora em interação com seus alunos, com o conteúdo, com a gestão da classe, ou seja, possibilitando o diálogo com vários outros aspectos da cultura escolar e da inserção profissional.

Diante de um cenário de disputa por concepções de formação de professores de matemática, o PIBID aparece como forte aliado, decorrente da necessidade de se implementar novas políticas sobre a docência na educação básica, por meio das reivindicações postas pela comunidade educativa. Opera no âmbito da formação inicial para os estudantes de licenciatura, ao mesmo tempo em que é um espaço de formação continuada para os professores da escola básica. $\mathrm{Na}$ medida em que aproxima a universidade da escola, favorece uma ampla discussão sobre os saberes docentes, sobre prática e teoria e estratégias de ensino-aprendizagem contextualizadas com a realidade do aluno de modo a que sejam significativas e problematizadoras.

\section{O PIBID Na DisPuta Simbólica} PELA FORMAÇÃO DE PROFESSORES DE MATEMÁT ICA

A partir das dificuldades que enfrentam as licenciaturas com relação à valorização profissional e, também, aos conhecimentos pedagógicos necessários à compreensão do referencial disciplinar na sua perspectiva curricular para a educação básica, é implementado o PIBID. Este aparece em um contexto em que há necessidade de qualificação da formação inicial, como possibilidade de 
reconhecimento da carreira e do profissional, auxiliando na oferta desses cursos, de modo a que não sejam vistos como cursos esquecidos, fáceis, sem apoio ou preteridos pela universidade. Dessa forma, Gatti (2014) e André (2018) apontam que o PIBID apresenta resultados positivos quanto ao estímulo aos jovens para ingressarem e permanecerem na docência, além da valorização das licenciaturas.

Como já dito, o PIBID foi criado pelo MEC em parceria com a CAPES no ano de 2007, quando instituições de ensino superior puderam apresentar projetos de iniciação à docência. No entanto, somente em 2009 foi publicada a portaria 122 , que o definiu no âmbito da CAPES, possibilitando a divulgação, em seguida, de novo edital para apresentação de propostas das instituições de ensino superior. Em 2010, o edital se expandiu, tornando possível a entrada de instituições do ensino superior municipais e comunitárias. Outros editais foram publicados em 2011, 2012 e 2013, tendo duração de quatro anos. Em 2018, foi lançado novo edital, contendo alterações estruturais na proposta, mas preservando o seu propósito central de iniciação à docência.

No âmbito do PIBID, a UFRJ atendeu à chamada pública de dezembro de 2007, apresentada conjuntamente pelo Ministério da Educação (MEC), Fundação Coordenação de Aperfeiçoamento de Pessoal de Nível Superior (CAPES), e Fundo Nacional de Desenvolvimento da Educação (FNDE), que fomentavam a iniciação à docência de estudantes das instituições federais de educação superior e tinham como objetivo preparar a formação de docentes em nível superior, em cursos de licenciatura presencial, para atuar na educação básica pública ${ }^{4}$.

No contexto da UFRJ, a matemática é inserida como subárea logo no primeiro edital, envolvendo quatro escolas públicas de Ensino Médio da rede estadual, 14 estudantes bolsistas do curso de licenciatura em matemática, três professores indicados pelas escolas parceiras para atuarem como supervisores e uma professora da universidade como coordenadora. O objetivo inicial do PIBID UFRJ Matemática consistia na redução da defasagem de aprendizagem de conteúdos matemáticos que os alunos apresentavam desde o Ensino Fundamental, além de ajudar a minimizar a evasão no $1 .^{\circ}$ ano do Ensino Médio. Para isso, o grupo desenvolveu aulas de reforço no contraturno das escolas para os alunos do $1 .^{\circ}$ ano do Ensino Médio que participavam do projeto. Essas aulas eram pensadas e planejadas nas reuniões semanais do PIBID. Nessas reuniões, os licenciandos tinham espaço para relatar fatos, acontecimentos e experiências vivenciadas no espaço escolar. Um dos desafios do grupo era tornar a matemática mais atrativa e que os alunos perdessem o medo diante dos conteúdos da disciplina. Daí a ênfase na criação de jogos didáticos, constantemente avaliados e remodelados.

Neste estudo, nos interessa saber se a passagem pelo programa foi capaz de favorecer a inserção profissional docente, se contribuiu com saberes docentes próprios da realidade do professor de matemática. Parece-nos relevante destacar a importância da temática ao considerarmos a especificidade da área, tendo em vista que as licenciaturas, no caso da matemática, ainda carecem de estudos e propostas que articulem a formação inicial com a inserção profissional docente, na perspectiva de que o desenvolvimento profissional se dá desde a formação inicial, passa pela socialização profissional e pela

${ }^{4}$ Conforme descrito no site da instituição. Disponível em http://www.pibid.pr1.ufrj.br/index.php/2012-12-17-16-28-24/pibid-naufrj (acesso em junho de 2015). 
formação continuada. Ao compreendermos como ocorre a inserção profissional de uma professora de matemática que vivenciou o PIBID, pretendemos contribuir para a discussão sobre a formação de professores e em que medida a inserção se modifica devido à especificidade da área.

\section{O CASO DE UMA PROFESSORA DE MATEMÁTICA}

A trajetória da professora tem um significado decisivo para o entendimento do estudo de caso etnográfico e reconhecer suas expectativas com relação à profissão, reconstituindo sua memória formativa, é um passo necessário para a compreensão da maneira como exerce a docência. Como aponta Velho (1994), a noção de biografia é fundamental e, segundo ele, "a trajetória de um indivíduo passa a ter um significado crucial como elemento não mais contido mas constituidor da sociedade" ( $p$. 100), e é a partir da noção de biografia que a memória desse indivíduo se torna socialmente relevante.

Diante da memória reconstituída da professora podemos compreender a noção de projeto, proposta por Velho (1994), enquanto "conduta organizada para atingir finalidades específicas" (p. 101). No caso, queremos reconstituir a história de Marina $^{5}$ enquanto um indivíduo que faz projetos, na sua individualidade singular, e que, baseado em sua memória sobre a escola, família e religião, faz uma escolha intencional pela carreira docente. Envolvemos valores, ações, desejos que dão significado à vida, e a própria noção de identidade.

Marina é a terceira filha de uma família residente no bairro da Tijuca, zona norte da cidade do Rio de Janeiro, Brasil, e foi nesse bairro que cresceu e cursou a Educação Básica, tendo feito a Educação Infantil, o Ensino Fundamental e Médio em escolas privadas, de alto prestígio na região. Ela tem 27 anos e é professora da Rede Municipal de Educação do Rio de Janeiro, onde atua do $6 .^{\circ}$ ao $9 .^{\circ}$ ano do Ensino Fundamental, tendo ingressado na escola no ano de 2015.

Durante a formação inicial, Marina ingressou no PIBID por recomendação de uma amiga do curso. Foi selecionada para fazer parte do grupo de matemática e explica que "acabou acontecendo", tornando-se a sua primeira experiência “profissional”. No PIBID UFRJ Matemática atuou no Ensino Médio em uma escola estadual e as reuniões aconteciam semanalmente; nessas reuniões, os bolsistas do projeto compartilhavam as experiências vivenciadas na escola e criavam atividades, que eram desenvolvidas no contraturno com alunos da escola estadual que tinham dificuldade em matemática ou interesse em aprender mais.

Marina é uma professora de matemática, egressa de uma universidade pública, atuante em uma escola pública municipal. A professora concluiu o curso de licenciatura em matemática em 2013 e ingressou na instituição onde atua em 2015. Sua chegada à escola foi marcada por um início em que precisou aprender os ritos e códigos da instituição, ou, em suas palavras, aprender "a se virar". Essa experiência foi caracterizada pelo seu primeiro dia como professora, pois sem conhecer a escola ou mesmo os alunos foi convidada a substituir um professor ausente.

A partir da ideia de projeto mencionada no início desta seção, entendemos que é possível depreender que a trajetória de Marina possibilita a formulação de seu projeto de vida profissional, por meio do estabelecimento de

${ }^{5}$ Os nomes utilizados são fictícios, respeitando os princípios éticos em pesquisas sociais e humanas. 
objetivos e fins claros quanto à escolha da carreira docente diante da influência da sua família por áreas distintas, além do ingresso em uma universidade pública, exceção diante da expansão do ensino privado superior no cenário educacional brasileiro. Marina também apresenta um perfil diferenciado no que se refere a sua origem social e econômica, posto que não trabalhou ou exerceu a docência ao longo da graduação, o que fez com que pudesse se dedicar integralmente aos estudos, além de ter estudado em escolas privadas consideradas de alto prestígio durante a educação básica.

Marina constrói seu projeto enquanto professora de matemática a partir da memória de sua trajetória escolar, seu gosto pela área e a lembrança de professores de sua escolarização anterior, fragmentos importantes do passado para que resista às dificuldades da carreira, como os baixos salários e a desvalorização da profissão.

A escola municipal em que Marina trabalha não apresenta um programa específico para os professores iniciantes. A única professora que está iniciando a carreira profissionalmente é Marina, sujeito desta investigação. Existem três professoras que estão ingressando na rede municipal, embora não seja sua primeira experiência profissional. A diretora da escola busca atualizar os novos professores quanto às regras do município, às orientações curriculares e aos procedimentos da escola. Todos participam dos centros de estudos e a única diferenciação exposta pela gestão ocorre na escolha das turmas, em que os professores mais antigos têm prioridade.

\section{A INSERÇÃO PROFISSIONAL DE} MARINA: ASPECTOS FACILITADORES E DIFICULTA DORES

Para compreender a inserção profissional de Marina, adentramos no cenário da escola e da sala de aula aonde a professora iniciante atua, descortinando um olhar mais atento aos processos de imersão na escola e de suas práticas pedagógicas. Foi possível depreender aspectos que tocam no contexto institucional, na relação com os pares e com os alunos e na visão de ensino da matemática.

Com relação ao contexto institucional no momento de inserção profissional, a visão da professora sobre a sua chegada foi de apoio e acolhimento, pois seus colegas professores foram fundamentais ao fornecerem dicas sobre os alunos e a escola. No entanto, chama a atenção para determinados aprendizados que precisou adquirir sozinha, como relata a seguir:

tem coisas que a diretora não vai falar, tipo assim: "você vai fazer chamada, pega o diário...". Cadê a pauta? Onde eu pego?... E aí os alunos às vezes me diziam: "olha, tem que fazer assim”, mas aí eu tinha que perceber quando eles estavam me enrolando, tipo, "os professores deixam fazer isso e isso"; aí eu tinha que saber quando eles estavam me enrolando e quando não, e com o tempo eu fui pegando o jeito, fui observando outros professores, na hora de subir, na hora de descer para o recreio, como eles faziam, como era o esquema de liberar mais cedo, liberar mais tarde. Tudo na escola eu fui me incorporando vendo no dia a dia mesmo, mas no início foi isso. (Marina, entrevista, 16/11/2016)

Marina precisou aprender determinadas regras do cotidiano escolar no próprio dia a dia, observando outros professores, perguntando aos alunos, e tendo que criar uma expertise para averiguar quando os estudantes a estavam ajudando e quando forneciam informações em benefício próprio, dado que a professora ainda era uma estranha no ambiente por não conhecer o funcionamento da escola. Ela não estava familiarizada com as regras, normas, símbolos e códigos internos da instituição, por isso precisou recorrer aos mais 
experientes. Segundo Marcelo (2010), “nesse momento, os novos professores aprendem e interiorizam normas, valores e condutas, etc., que caracterizam a cultura escolar na qual se integram" (p. 30). Essa fase de reconhecimento do ambiente de trabalho, seja com a ajuda dos alunos ou dos professores da instituição, é fundamental para que a professora iniciante consiga, através da experiência cotidiana, conhecer a cultura e o clima institucional. As relações que se estabelecem configuramse como um elemento importante para o desenvolvimento profissional.

No tocante ao relacionamento com os pares, um aspecto marcante da inserção profissional de Marina é o seu isolamento, que acaba por dificultar sua inserção profissional. $O$ isolamento profissional, tal como demonstra Cochran-Smith (2012), é característica comum a professores iniciantes, pois, geralmente, enfrentam sozinhos a tarefa de ensinar, cabendo aos alunos serem os únicos testemunhos da ação docente. Esse isolamento é favorecido pela arquitetura escolar, pelas condições de trabalho, pela desvalorização profissional, pela carga horária, dentre outros fatores. Nesse sentido, Bird e Little (1986, cit. em Marcelo, 2010) assinalam que, embora o isolamento facilite a criatividade individual e libere os professores de algumas das dificuldades associadas ao trabalho compartilhado, também os priva da estimulação do trabalho pelos companheiros e da possibilidade de receber o apoio necessário para progredir ao longo da carreira. Esta situação muitas vezes se intensifica em professores iniciantes e, nesses casos, pode ser extremamente prejudicial para o seu desenvolvimento profissional.

Sobre o isolamento docente, Marina reconhece que se sente distante dos demais professores, o que atribui a uma característica sua, pois reconhece que ainda se retrai diante do grupo e não aproveita os espaços de colaboração. Não identifica nenhum problema em sua relação com os demais professores; ao contrário, acredita que essa relação pode trazer benefícios a sua formação, por isso aponta que precisa se esforçar mais nesse sentido. A professora iniciante explica que prefere ficar "mais na dela" porque esses momentos auxiliam para o seu descanso e reconhece que os professores mais antigos são mais expansivos, enquanto ela é mais introspectiva. Também relata que os assuntos geralmente são sobre política e que prefere não opinar, o que faz com que se ausente na maior parte do tempo, como se explicita na passagem a seguir:

Depois, Marina comenta sobre a sua relação com os outros professores, que está tentando melhorar nisso e que considera que é uma característica dela não "puxar muito assunto", porque não gosta muito de falar sobre política ou sobre a escola, tendo em vista que eles estão há mais tempo que ela. No entanto, ressalta que são receptivos e que gostaria de melhorar isso nela mesma. Também comenta que nas reuniões, como conselhos de classe, tenta falar mais porque é a professora "oficial" da turma do $7 .^{\circ}$ e $8 .^{\circ}$ ano. Pergunto sobre a reunião de pais que ocorreu no sábado e ela responde que foi boa. (Diário de campo, 26/10/2016)

$\mathrm{O}$ isolamento, mesmo sendo identificado como uma dificuldade particular de Marina, pode ser entendido também como uma dificuldade da professora iniciante de se integrar a esse grupo, formado por professores experientes, extrovertidos e que gostam de interagir. Diante disso, a professora prefere observar ainda como uma estrangeira frente ao coletivo. Para Cochran-Smith (2012), o isolamento é um movimento duplo: quanto mais a professora iniciante se sente distante do grupo de professores, mais busca se isolar diante das dificuldades encontradas.

Cochran-Smith (2012) alerta para as diferentes direções que os professores iniciantes tomam ao chegar na escola, o que está relacionado com múltiplos fatores, como as suas práticas individuais, quem eles são, o que trazem, como ensinam, suas características, o que influencia na sua inserção profissional. 
Porém, mais do que a personalidade dos professores ou se eles "nasceram" ou não para a docência, as maneiras como as características desses professores iniciantes se relacionam com os recursos disponíveis, o que aprenderam na formação inicial, que tipo de oportunidades têm para refletir criticamente e trabalhar conjuntamente na cultura escolar marcam esse momento. Por essa razão, é necessário que os iniciantes tenham oportunidade de conversar com professores mais experientes sobre o ensino que desenvolvem e as estratégias utilizadas para o enfrentamento deles, abrindo espaço para que os professores possam trocar experiências, discutindo suas práticas escolares e oferecendo sugestões que possam ser fonte de apoio, como evidenciam Nono e Mizukami (2006).

Sobre a relação com os seus alunos, é importante destacar que, para os professores iniciantes, administrar algumas incertezas, bem como o papel de autoridade e a sua própria identidade profissional, são questões complicadas. Marina também enfrenta conflitos no que se refere ao comportamento dos alunos, à indisciplina e ao próprio sentido de discência. Segundo a professora investigada, há uma grande diferença entre os alunos do $6 .^{\circ}$ ano do Ensino Fundamental e os demais estudantes. Os do $6 .^{\circ}$ chegam com maior defasagem com relação ao conteúdo, há mais brigas entre eles, o que demanda da professora maior intervenção, exigindo mais tempo e paciência.

No seu primeiro ano letivo como professora nessa escola, Marina ficou responsável por duas turmas e em 2017 as três turmas do 6. ${ }^{\circ}$ ano foram reagrupadas em duas, das quais Marina é a professora. É possível perceber como ela entende esse conflito na passagem a seguir:

Eu particularmente tenho muita dificuldade com o $6 .^{\circ}$ ano, não sei se é perfil do professor, mas eu realmente não consigo. Eu no início achava que era a turma, mas depois eu comecei a ver que era uma coisa da idade, do ano ali... Não sei se eles estão ali no ano de adaptação, no ano de amadurecer com o $5 .^{\circ}$ ano para baixo, que eu imagino que deva ser até pior, então esse $6 .^{\circ}$ ano é essa mudança. (Marina, entrevista, 19/05/2017)

Marina comenta essa dificuldade nas turmas do $6 .^{\circ}$ ano, o que é possível verificar também na maneira como ela interage com esses alunos e nas estratégias de ensino que utiliza.

A aula tem início com bastante barulho e a professora alerta para as mudanças do $6 .^{\circ}$ ano com relação ao conteúdo e comportamento, aumentando o tom de voz e chamando a atenção de quem estava de boné e com celular. Ela inicia a aula comentando sobre raiz e múltiplos, mas é interrompida por dois alunos que se desentendem; então Marina diz que irá tirar pontos deles. ... A aula termina e nos corredores ela diz para mim que está ficando sem paciência com essa turma. (Diário de campo, 04/11/2016)

Em seguida, fomos para a turma 1604, Marina fez uma reorganização dos lugares marcados e depois retomou a explicação de área e perímetro. Falou comigo, durante o recreio, que já havia terminado com essa turma o conteúdo e a apostila não estava boa; também não sabia o que o professor anterior havia dado. Ela inicia a explicação com muito barulho e com muita dificuldade para gerir a classe, os alunos não conseguem responder às questões corretamente. Ela explica o que é perímetro e área e depois demonstra na janela da sala, apontando a lateral para saberem como calcular a área. Depois, passa exercícios na apostila e os que estão sem o material formam duplas para, posteriormente, ela corrigir no quadro. Alguns participam, mas outros estão dispersos. (Diário de campo, $16 / 11 / 2016)$

O relacionamento estabelecido entre professora e alunos pode ser entendido também como um primeiro choque cultural 
da professora com seu ambiente de trabalho. Como os alunos representam um papel importante no desenvolvimento profissional dos professores iniciantes, o choque cultural vivenciado por Marina representa também uma outra configuração do jovem que vai à escola, talvez diferente do imaginário construído pela docente ou mesmo do ambiente escolar no qual tenha crescido. Para Tardif (2002), ao chegar à escola a professora iniciante encontra alunos "reais", que não correspondem à imagem esperada ou mesmo desejada, ou seja, estudiosos, dependentes, sensíveis às recompensas e punições. Quando a professora sai de sala cansada e diz que não sabe o que fazer com as turmas, demonstra que se interessa pelo aprendizado deles e que a falta de interesse pelo conteúdo a aflige, ao mesmo tempo em que aparenta dizer que faltam estratégias para ensinar a esses alunos reais.

Outra característica de Marina, que dificulta e facilita a sua inserção profissional, é a sua visão da matemática enquanto um conhecimento a ser transmitido. Essa concepção epistemológica está relacionada a quem ela é, suas experiências enquanto estudante, a expectativa que tem de si e dos alunos, o momento em que se encontra profissionalmente e a visão da disciplina que leciona. Mariana nutre altas expectativas de si e da área, o que lhe permite sentir-se segura diante dos desafios.

As aulas de Marina são majoritariamente organizadas por meio dos exercícios da apostila e do livro didático. Essa prática do exercício ocorre por meio da memorização do conteúdo e da repetição, e o diálogo estabelecido em sala se dá em um modelo de comunicação em que a professora pergunta, o aluno responde e a professora avalia, não sendo possível identificar estratégias variadas, grupos de investigação, problematizações por parte dos alunos com relação ao conteúdo, posicionamentos contrários, desafios ou um cenário que modifique o estilo tradicional de ensino da professora.

$\mathrm{Na}$ visão de Marina, a matemática requer muito exercício, pois é uma forma de colocar em prática o que foi aprendido, perceber os erros e identificar as dificuldades, como explica a seguir:

porque a matemática tem que exercitar muito, você aprende que $\mathrm{X} x \mathrm{X}=\mathrm{X}^{2}$, aprende a multiplicar polinômio - acabei de sair da aula de polinômio -, aí você fala: “entendi!", mas quando você se depara com o exercício é que você vai colocar em prática o que você acabou de aprender, entendeu?! Ali você vai ver os seus erros, quais foram as dificuldades que apareceram e, quando é $2 \mathrm{X}$, aí o aluno já não sabe, então essas coisas tem que exercitar. (Marina, entrevista, 19/05/2017)

O ensino transmissivo é uma escolha intencional, pois Marina compreende que dessa maneira os alunos vão aprender mais e melhor, justificando que não varia as estratégias de ensino-aprendizagem, pois foi dessa forma que aprendeu na escola e na graduação. Considera que, quando os alunos têm oportunidades de experienciar outras formas de aprendizado, o conteúdo precisa, também, ser desenvolvido de forma expositiva e com exercício em seguida, pois por meio de jogos, passeios e filmes não é possível internalizar bem, como relata a seguir:

Eu poderia utilizar um pouquinho mais porque eu sei que os alunos também gostam, às vezes eles ficam um pouco mais atentos na aula porque é uma atividade mais lúdica, mas eu não... eu não sou uma professora que vou ficar dando atividades assim toda a aula, vou ficar procurando cartolinas, cortando, preparando jogos... (Marina, entrevista, 19/05/2017)

A concepção epistemológica de Marina em relação ao ensino de matemática parece ser um dos fatores de isolamento dos pares, seja pelas estratégias de ensino que utiliza ou pela especificidade da área e sua posição privilegiada no currículo escolar. De algum modo, essa sua condição pode ser caracterizada como um 
indutor de "privatização da prática". CochranSmith (2012) chama a atenção sobre como o ensino tem sido considerado um trabalho privado, sendo o ofício docente concebido como uma atividade altamente individualizada, atrás de portas fechadas e no isolamento dos outros professores. A autora utiliza o constructo "desprivatização da prática"6 para o interromper do ensino enquanto ato privado, estimulando a colaboração daqueles que também estão dispostos a tornar o seu trabalho público e aberto a críticas.

A concepção epistemológica de ensino de matemática revelada pela professora incide diretamente na mobilização de seus saberes profissionais. O saber docente é plural, heterogêneo e ocorre em diferentes lugares de atuação. Tardif (2002) sustenta que o professor não vai utilizar ao longo da sua vida profissional uma única concepção de ensino, pois elas variam em função da sua realidade cotidiana e de sua história de vida; portanto, para ele, "se os saberes dos professores possuem uma certa coerência, não se trata de uma coerência teórica nem conceitual, mas pragmática e biográfica” (p. 65).

Marina explica que a maneira como ensina é a mesma com a qual foi ensinada na escola e na formação inicial, ou seja, um professor à frente que explicava o conteúdo, os alunos escreviam e exercitavam. Ela estudou a maior parte da sua vida em uma escola privada no mesmo bairro de sua residência, e a instituição é tradicionalmente conhecida por ser uma escola com bons resultados nas avaliações externas.

Não basta o professor conhecer em profundidade os procedimentos matemáticos e saber utilizá-los, na resolução de problemas ou de exercícios, é importante que saiba justificar tais procedimentos, conheça de que maneira foram historicamente produzidos, de modo a contextualizá-los. Assim, a inserção profissional de Marina, uma professora iniciante de matemática que passou pelo PIBID, enfrenta aspectos dificultadores, como o isolamento dos professores, o relacionamento conflituoso com os alunos, o choque cultural com esse grupo de estudantes. Mas existem aspectos facilitadores, como a segurança em si mesma e a valorização da área, a matemática.

\section{DA INICIAÇÃO À INSERÇÃO: OS LIMITES E CONTRIBUIÇÕES DO PIBID}

Como procuramos salientar, a inserção profissional de Marina é marcada por um isolamento de sua prática de ensino, sem trocas de experiência entre pares. Além disso, sua concepção epistemológica de ensino transmissivo tem como principais fontes de saberes a sua formação escolar anterior e a formação inicial, notadamente através dos sinais de um estudo da matemática com forte influência do bacharelado. Diante dessa análise, nos questionamos sobre o papel do PIBID na formação, um programa de iniciação à docência pensado e experimentado especialmente no contexto de um programa com uma marca colaborativa. Qual a contribuição do programa para ela? Porque a professora não recorre às experiências do PIBID em seu cotidiano?

O PIBID assume um papel destoante, porém importante, em sua formação. Marina considera que o PIBID foi uma importante contribuição para que desenvolvesse um repertório de atividades e não chegasse à escola em que trabalha totalmente perdida. O conhecimento do contexto profissional foi para ela um dos aprendizados mais significativos propiciados pelo programa, pois contribuiu para que desenvolvesse uma maior segurança para ensinar, já que estivera em situações concretas de ensino-aprendizagem anteriormente; possibilitou também que refletisse sobre as atividades que deveria usar e o porquê. Sobre essa contribuição, Marina afirma:

Sem o PIBID eu não sei se teria um impacto ainda maior, mas eu acho que sim, porque é

${ }^{6}$ Do inglês "deprivatization of practice". 
na prática que a gente aprende mais; então na faculdade a gente aprende um monte de coisa nas matérias, mas o PIBID foi a experiência na prática que eu tive, então realmente eu acho que fez diferença sim. Me deu um pouco mais de segurança para lidar com a turma, porque - eu já falei, até - quando eu cheguei aqui já me subiram para eu entrar numa turma que eu nem sabia qual era, no meio do ano. (Marina, entrevista, $16 / 11 / 2016$ )

A passagem pelo PIBID pode ser considerada como uma fonte de conhecimento para a professora iniciante, que reconhece a contribuição do programa para a elaboração de e reflexão sobre atividades de ensino de matemática. Ela destaca que o PIBID foi seu primeiro contato com a sala de aula e a importância desse momento para uma professora em processo de inserção profissional.

Para mim o PIBID foi muito mais assim de ter uma prática, porque foi umas das primeiras, se não foi a primeira prática em aula - eu dando aula para aluno, apesar de não ser uma turma minha; então na prática você vai aprendendo, né? Ali o aluno, ensinar como que é, o método melhor... então foi o meu primeiro contato, então foi muito bom. As questões das atividades que a gente fazia lá, porque eram diferentes as atividades, porque o PIBID tinha essa proposta, pelo menos na matemática, atividades que auxiliassem o ensino da matemática, pelo menos na minha época lá esse era o foco, eu lembro que a gente ficava montando atividades para isso. E, sinceramente, é legal, é divertido, mas não é o que eu pretendo usar. (Marina, entrevista, 19/05/2017)

Embora Marina reconheça a importância do programa em sua formação, ao se tratar da sua atuação como professora de matemática iniciante explica que não é possível atribuir muito do seu ensino atual ao que foi desenvolvido no PIBID, já que se faz necessário pensar em outras formas de articular o que foi aprendido no programa à rotina de uma professora iniciante. Não há uma memória negativa do que foi vivido no programa - ao contrário: ela acredita que o PIBID deva continuar em sua proposta. Isso ocorre pela disputa acerca do que conta como formação de professores de matemática. Ainda que a professora tenha vivenciado o programa durante um ano em sua formação inicial, teria sido suficiente para romper com a lógica de formação vigente nos cursos de licenciatura em matemática? A lógica subjacente ao $3+1$ (três anos de bacharelado mais um ano de licenciatura) ainda permanece como estruturante nesses cursos, prevalecendo uma separação entre as disciplinas de "conteúdo" e as disciplinas de "ensino".

A atribuição de sentido que Marina imprime ao projeto nos faz refletir sobre as possibilidades e limitações do PIBID, tendo em vista que é um projeto de iniciação à docência e não de inserção profissional docente portanto, objetiva "oportunidades de criação e participação em experiências metodológicas, tecnológicas e práticas docentes de caráter inovador e interdisciplinar que busquem a superação de problemas identificados no processo de ensino-aprendizagem" (Decreto n. ${ }^{\circ} 7.219$, art. $3^{\circ}$, inciso IV).

Como afirma Fonseca (1999), apesar da singularidade expressa no contexto do projeto PIBID UFRJ Matemática, é preciso levar em consideração as realidades de cada projeto para compreender a leitura que tem sido feita dessa política educacional. E, tal como evidenciam as pesquisas, o PIBID vem demonstrando ser um diferencial na formação e atuação dos futuros professores, além de ser um contributo significativo na parceria universidadeescola básica. Nesse sentido, as pesquisas e avaliações dos subprojetos se mantêm sendo significativas.

\section{CONSIDERAÇÕES FINAIS}

A pesquisa apresentou aspectos facilitadores e dificultadores da inserção profissional de uma 
professora de matemática, evidenciando suas impressões sobre o PIBID e a importância do acolhimento por parte da gestão escolar e dos pares nessa fase da carreira. Sua passagem pelo PIBID contribuiu para amenizar o "choque de realidade", favorecendo um reconhecimento do contexto profissional. Proporcionou a Marina uma maior segurança em sala de aula e possibilidades variadas de estratégias de ensino. No entanto, as dificuldades do início da profissão e a própria concepção epistemológica da professora fazem com que o seu ensino seja compreendido enquanto ato transmissivo, e isso se justifica e explica pela formação que teve ao longo de sua escolarização e no decorrer de sua graduação, cuja proposta de formação de professores recebeu uma forte influência da formação oferecida ao bacharelado.

Concluímos que, para que a inserção profissional se dê em condições mais acolhedoras, parece relevante que existam espaços de colaboração, troca de experiências entre iniciantes e experientes, formando uma espécie de comunidade de aprendizagem em que os professores possam falar sobre o ensino que praticam. Por conseguinte, é necessário pensar em programas de indução profissional, para que os iniciantes recebam algum tipo de acompanhamento intencional dos mais experientes nos primeiros anos do seu ciclo de vida profissional.

Consideramos necessário que os professores iniciantes tenham a oportunidade de rever suas crenças sobre o ensino em espaços de colaboração, entendendo que o aprendizado sobre a docência ocorre ao longo da vida. Programas específicos de inserção com indução podem ajudar não só os professores que estão chegando à escola, mas os experientes, que também são convidados a refletir sobre as práticas de ensino que desenvolvem. Além disso, é necessário garantir a permanência e expansão de programas de iniciação à docência, como o PIBID, que são aliados importantes na disputa por uma formação de professores que reconhece a escola como espaço cultural e político de atuação profissional.
Os temas iniciação, inserção e indução profissional necessitam ganhar cada vez mais espaço nas discussões de formação de professores entendendo que esse processo precisa ocorrer de maneira articulada, pois a formação deve acontecer no contexto da profissão. Assim, o estudo de caso etnográfico proposto auxilia a compreensão de que a escola é indispensável para pensar o processo de inserção profissional. A escola, a comunidade e a universidade, de maneira integrada, devem visar um objetivo comum de formação einserção desses professores, pois são espaços simbólicos de enriquecimento social, cultural e político. É recomendável que os professores iniciantes possam se organizar, representar e comunicar de forma a que os alunos compreendam mais profundamente o conteúdo. A colaboração entre os colegas, quando existe, pode fazer com que ultrapassem suas dificuldades em um processo de socialização profissional.

\section{REFERÊNCIAS}

André, M. (2018). Professores iniciantes: Egressos de programas de iniciação à docência. Revista Brasileira de Educação, 23, 1-20.

Becker, H. S. (1997). Métodos de pesquisa em ciências sociais. São Paulo, Brasil: Hucitec.

Campelo, T. S., \& Cruz, G. B. (2017). O PIBID e a aprendizagem da docência: A intervenção do professor-supervisor. Crítica Educativa, 3(2, n. ${ }^{\circ}$ especial), 188-203.

Cochran-Smith, M. (2012). A tale of two teachers: Learning to teach over time. Kappa Delta Pi Record, 48(3), 108-122.

Cochran-Smith, M., \& Lytle, S. (1999). Relationships of knowledge and practice: Teacher learning in communities. Review of Research in Education, 24, 249-305.

Cruz, G. B. (2019a). Prática, pesquisa \& formação docente: Narrativas do PIBID Pedagogia da UFRJ. Curitiba, Brasil: CRV.

Cruz, G. B. (2019b). Professores principiantes e sua visão acerca da formação: Aspectos 
didáticos-pedagógicos. Profesorado. Revista de Currículum y Formación de Profesorado, 23(3), 93-112.

Ferreira, A. C., \& Moreira, P. C. (2013). O lugar da matemática na licenciatura em matemática. Bolema, 27(47), 981-1005.

Fiorentini, D., \& Oliveira, A.T. (2013). O lugar das matemáticas na licenciatura em matemática: Que matemáticas e práticas formativas? Bolema, 27(47), 917-938.

Fiorentini, D., Passos, C. L. B., \& Lima, R.C. R. (Orgs.). (2016). Mapeamento da pesquisa acadêmica brasileira sobre o professor que ensina matemática: Período 2001-2012. Campinas, SP, Brasil: FE/UNICAMP.

Fonseca, C. (1999). Quando cada caso não é um caso: Pesquisa etnográfica e educação. Revista Brasileira de Educação, 10, 58-78.

Gatti, B. (2010). A formação de professores no Brasil: Características e problemas. Educação \& Sociedade, 31(113), 1355-1379.

Gatti, B. (2014). A formação inicial de professores para a educação básica: Pesquisas e políticas educacionais. Estudos em Avaliação Educacional, 25(57), 24-54.

Gatti, B. A. (2008). Análise das políticas públicas para formação continuada no Brasil, na última década. Revista Brasileira de Educação, 13(37), 57-70.

Geertz, C. (1989). A interpretação das culturas. Rio de Janeiro, Brasil: LTC.

Huberman, M. (2000). O ciclo de vida profissional dos professores. In A. Nóvoa (Org.), Vidas de professores (2. ${ }^{\text {a }}$ ed., pp. 31-61). Porto, Portugal: Porto Editora.

Marcelo, C. (1999). Formação de professores: Para uma mudança educativa. Porto, Portugal: Porto Editora.

Marcelo, C. (2009). Desenvolvimento profissional docente: Passado e futuro. Sísifo. Revista de Ciências da Educação, 8, 7-22.

Marcelo, C. (2010). O professor iniciante, a prática pedagógica e o sentido da experiência. Formação Docente, 3(3), 11-49.

Marcelo, C. (2011). Políticas de inserción en la docencia: De eslabón perdido a puente para el desarrollo profesional docente. In Programa de Promoción de la Reforma Educativa en América Latina y el Caribe (PREAL). Serie Documentos $n$. 52. Disponível em http://www. ub.edu/obipd/docs/politicas de insercion a la docencia del eslabon perdido al puente para el desarrollo profesional docente garcia c m.pdf (acesso em 24 junho, 2019).

Marcelo, C., \& Vaillant, D. (2017). Políticas y programas de inducción en la docencia en Latinoamérica. Cadernos de Pesquisa, 47(166), 1224-1249.

Nono, M. A., \& Mizukami, M. G. N. (2006). Processos de formação de professoras iniciantes. Revista Brasileira de Estudos Pedagógicos, 87(217), 382-400.

Nóvoa, A. (2009). Professores: Imagens do futuro presente. Lisboa, Portugal: Educa.

Shulman, L. (1986). Those who understand: Knowledge growth in teaching. Educational Researcher, 15(2), 4-14.

Tardif, M. (2002). Saberes docentes e formação profissional (4. ${ }^{\mathrm{a}}$ ed.). Rio de Janeiro, Brasil: Vozes.

Veenman, S. (1984). Perceived problems of beginning teachers. Review of Educational Research, 54(2), 143-178.

Velho, G. (1994). Projeto e metaforfose: Antropologia das sociedades complexas. Rio de Janeiro, Brasil: Jorge Zahar Ed.

Weber, F. (2007). Guia para a pesquisa de campo: Produzir e analisar dados etnográficos. Petrópolis, Brasil: Vozes.

\section{LEg ISL AÇÃo CONSULTADA}

Decreto n. ${ }^{\circ} 7.219$, de 24 de junho de 2010. Dispõe sobre o Programa Institucional de Bolsa de Iniciação à Docência (PIBID) e dá outras providências. Brasília, DF, Brasil. Disponível em http://www.planalto.gov.br/ ccivil 03/ ato2007-2010/2010/decreto/d7219. $\underline{\mathrm{htm}}$ 
THE PROFESSIONAL INSERTION OF A PIBID SCHOLARSHIP STUDENT: THE CASE OF A MATH TEACHER

\begin{abstract}
The paper focuses on the professional insertion of a mathematics teacher that held the PIBID scholarship and nowadays works on the second level of Elementary School in a municipal public school in Rio de Janeiro, Brazil. An ethnographic case study was performed, in a way that the teacher's experiences, education and expectations were understood by means of in-depth interviews and participating observation. Theoretically, the paper dialogues with Cochran-Smith, Fiorentini and Marcelo Garcia. The results show that: there's a tendency to the isolation by the beginning teacher; there's a force of the area and an epistemological belief in transmissive teaching; the PIBID scholarship appears as a contribution in what refers to the knowledge of the professional context.
\end{abstract}

KeYwORDS: Professional insertion of teachers; Math teacher; Ethnographic case study

\section{LA INSERCIÓN PROFESIONAL DE UN EGRESO DEL PIBID：EL CASO DE UNA PROFESORA DE MATEMÁTICA}

\section{RESUMEN}

El artículo se centra en la inserción profesional de una profesora de matemática que pasó por el PIBID y hoy actúa en los años finales de la Enseñanza Fundamental de una escuela pública municipal de Río de Janeiro, Brasil. Se realizó un estudio de caso etnográfico, de modo que las experiencias, la formación y las expectativas de la profesora fuesen comprendidas por medio de entrevistas en profundidad y observación participante. Teóricamente, el artículo dialoga con Cochran-Smith, Fiorentini y Marcelo García. Los resultados demuestran que: hay una tendencia al aislamiento por parte de la profesora principiante; existe una fuerza del área y una creencia epistemológica en la enseñanza transmisiva; el PIBID aparece como una contribución en lo que se refiere al conocimiento del contexto profesional.

Palabras clave: Inserción profesional docente; Profesora de matemática; Estudio de caso etnográfico

\footnotetext{
${ }^{\text {I }}$ Universidade Federal do Rio de Janeiro, Programa de Pós-Graduação em Educação, Brasil. ORCID: 0000-0003-1891-8285

II Universidade Federal do Rio de Janeiro, Faculdade de Educação, Brasil. ORCID: 0000-0001-5581-427X
} 